ORIGINAL ARTICLE

\title{
Patient reports of adverse events associated with acupuncture treatment: a prospective national survey
}

\author{
H MacPherson, A Scullion, K J Thomas, S Walters
}

Qual Saf Health Care 2004;13:349-355. doi: 10.1136/qshc.2003.009134

\begin{abstract}
See end of article for authors' affiliations

.....................

Correspondence to: Dr H MacPherson, Department of Health Sciences, University of York, Heslington, York YOI0 5DD, UK; hm18@ york.ac.uk
\end{abstract}

Accepted for publication 5 June 2004

\begin{abstract}
Objective: The primary aim was to establish from acupuncture patients the type and frequency of adverse events they experienced and attributed to their treatment. Secondary aims included the measurement of patient reported adverse consequences arising from advice received about conventional/prescribed medication or from delayed conventional diagnosis and treatment.

Methods: Postal survey of prospectively identified acupuncture patients. One in three members of the British Acupuncture Council ( $n=638$ ) invited consecutive patients to participate in the survey. Participating patients gave baseline data and consented to direct follow up by the researchers at 3 months. A structured questionnaire was used to collect data on perceived adverse events.

Results: 9408 patients gave baseline information and consent and 6348 (67\%) completed 3 month questionnaires. Responders were not dissimilar to non-responders for all known characteristics. 682 patients reported at least one adverse event over 3 months, a rate of 107 per 1000 patients $(95 \% \mathrm{Cl} 100$ to 115). Three patients reported a serious adverse event. The most common events reported were severe tiredness and exhaustion, pain at the site of needling, and headache. Patients receiving acupuncture treatment that was not funded by the NHS and patients not in contact with a GP or hospital specialist were less likely to report adverse events (odds ratios 0.59 and 0.66 , respectively). 199 (3\%) of responding patients reported receiving advice about conventional/prescribed medication, six of whom reported adverse consequences after taking the advice. Two patients reported delayed conventional treatment.

Conclusion: Patients report a range of adverse events but these do not prevent most patients seeking further acupuncture. This large scale survey supports existing evidence that acupuncture is a relatively safe intervention when practised by regulated practitioners.
\end{abstract}

$\mathrm{T}$ he increasing popularity of acupuncture in the west has led to growing demands for evidence of effectiveness and safety. ${ }^{12}$ There is a growing literature on adverse events associated with acupuncture, including more serious events such as pneumothorax and hepatitis. ${ }^{3}$ This literature has mostly consisted of case reports and retrospective surveys of practitioners. Better evidence has come recently from two prospective studies of adverse events reported by practitioners, ${ }^{56}$ supporting the assertion that "acupuncture is safe in competent hands". ${ }^{\prime}$ In these two surveys combined, over 60000 consultations were monitored and 86 significant nonserious adverse events were reported-most commonly nausea, fainting, and dizziness. ${ }^{5}{ }^{6}$ However, schemes which rely on practitioners reporting suspected adverse reactions are known to suffer from widespread underreporting. ${ }^{8}$ A more active role for patients in identifying adverse events is increasingly being advocated on the basis that patients are likely to provide more accurate reporting as well as having a legitimate interest in their own safety. ${ }^{8}$

With 2 million acupuncture treatments being provided in the UK each year by acupuncturists outside the National Health Service (NHS), ${ }^{9}{ }^{10}$ safety has clearly become a public health issue. ${ }^{3411}$ In addition to questions about the safety of acupuncture treatment itself, concerns have been raised that "since acupuncture is used by some practitioners as a complete system of medicine, it may constitute a risk of delayed conventional diagnosis (or treatment)" because "a sinister underlying cause" might be missed. ${ }^{3}$ Furthermore, it has been suggested that "practitioners have the unfortunate habit of (changing prescribed medication) which could be associated with important risks". ${ }^{3}$ It is important to examine the degree to which these speculated risks are demonstrated in practice.
In the UK there have been recent moves to establish statutory regulation of acupuncture. ${ }^{2}$ Four self-regulated professional associations of acupuncture, including the British Acupuncture Council (BAcC), have come together under the aegis of the Department of Health and the Prince of Wales' Foundation for Integrated Health and developed recommendations for the statutory regulation of acupuncture. Members of the BAcC have a minimum of 3 years of full time training or equivalent, have signed up to a code of practice with a requirement that only single use needles are used, and by and large practise outside the NHS. In the context of the recommendations for statutory selfregulation, this study sought to establish more clearly the evidence base for the safety of both acupuncture and acupuncturists.

Our primary aim was to establish prospectively the type and frequency of adverse events reported independently by patients over a 3 month period. The secondary aims were to identify the perceived adverse events associated with either advice about medication or about delayed conventional diagnosis or treatment.

\section{METHODS}

\section{Recruitment}

Over a 6 month period in 2002, all 1955 acupuncturists registered with the BAcC were invited to identify up to 60 consecutive patients aged over 18 and to give them a short questionnaire and consent form. Participating patients returned their baseline questionnaires and consent forms direct to the research centre and 3 months later they received postal questionnaires. We aimed to collect data from patients covering 30000 consultations to facilitate comparisons with 
Table 1 Sex and length of time in practice of BAcC practitioners who did and did not agree to participate in the study

\begin{tabular}{lll}
\hline & $\begin{array}{l}\text { Acupuncturists who did } \\
\text { not agree to participate } \\
\text { (n= 1317) }\end{array}$ & $\begin{array}{l}\text { Acupuncturists who } \\
\text { agreed to participate } \\
\text { (n=638) }\end{array}$ \\
\hline $\begin{array}{l}\text { Sex } \\
\text { Male }\end{array}$ & $566(42.2 \%)$ & $232(36.4 \%)$ \\
Female & $761(57.8 \%)$ & $406(63.6 \%)$ \\
Years in practice & $154(11.7 \%)$ & $66(10.3 \%)$ \\
$<2$ & $375(28.5 \%)$ & $162(25.4 \%)$ \\
$2-5$ & $329(25.0 \%)$ & $145(22.7 \%)$ \\
$5-10$ & $244(18.5 \%)$ & $111(17.4 \%)$ \\
$10-15$ & $148(11.2 \%)$ & $93(14.6 \%)$ \\
$15-20$ & $47(3.6 \%)$ & $43(6.7 \%)$ \\
$20-25$ & $20(1.5 \%)$ & $18(2.8 \%)$ \\
$>25$ & &
\end{tabular}

Comparison of sex: $\chi^{2}=5.87$ on $1 \mathrm{df}, \mathrm{p}=0.015$.

Comparison of length of time in practice: $\chi^{2}=20.41$ on $6 \mathrm{df}, \mathrm{p}=0.0023$.

$\chi^{2}$ test for trend $=13.86$ on $1 \mathrm{df}, p=0.0002$.

practitioners' reports of adverse events. ${ }^{56}$ The Northern \& Yorkshire multicentre research ethics committee gave ethical approval for this study.

\section{Data collection on adverse events}

The 3 month questionnaires provided data on patients' reporting on what they perceived to be adverse events, either caused directly by the acupuncture treatment or indirectly as a result of following the acupuncturist's advice about medication or from delayed conventional diagnosis or treatment. For the purposes of this survey we did not define an adverse event but, instead, provided patients with a checklist of possible events. This and the overall questionnaire, while not formally validated, were developed from two practitioner surveys. ${ }^{5}$ In contrast, "serious adverse events" were predefined as those resulting in admission to hospital or being permanently disabling or life threatening, ${ }^{12}{ }^{13}$ and patients ticked these categories if they believed them relevant. We also asked for details of adverse consequences resulting from both advice about medication and from delayed diagnosis or treatment. For patients who followed advice about medication we sent a short additional questionnaire asking about the type medication, whether the advice was to stop or reduce, and whether this advice had been discussed with their GP or specialist. With the patients' permission, all serious events and all cases of delayed diagnosis and treatment were followed up with a short telephone interview, clarifying the details of the event with questions from a checklist.

\section{Data analysis}

The representativeness of the practitioners and patients was assessed from the baseline data to facilitate an estimate of the extent to which we could generalise the results. The reported type and frequency of adverse events were tabulated, calculating the absolute risk in terms of an adverse event rate per 1000 patients over 3 months with 95\% confidence intervals. Relative risks were calculated as odds ratios (OR) of at least one adverse event occurring for key characteristics of practice using logistic regression, adjusted first for age and sex and then for relevant confounders simultaneously, thereby establishing evidence on risk factors.

\section{RESULTS}

\section{Practitioners}

1114 practitioners (52\%) responded and $638(33 \%)$ agreed to participate. The reasons given by practitioners who declined to participate were that they were too busy $(n=146)$, not in practice $(n=45)$, seeing too few patients $(n=35)$, retiring or moving away $(n=28)$, on holiday $(n=21)$, on a maternity break $(n=18)$, disapproving of the survey $(n=15)$, or other reasons $(n=60)$. Participating practitioners were significantly more likely to be female (64\% v 58\%; difference $6 \%$, $95 \%$ CI 1 to $10 ; p=0.015$ ) and to have been in practice for longer (table 1).

\section{Patients}

9408 patients agreed to participate in the study and 6348 $(67.5 \%, 95 \%$ CI 66.5 to 68.4$)$ completed questionnaires at 3 months. Table 2 shows that patients who completed the 3 month follow up questionnaire were significantly more likely to be female and older, and significantly less likely to be seeing an acupuncturist for the first time, having the NHS pay for their treatment, or being treated by a practitioner with less than 2 years experience.

The following analysis will focus on patients who returned adverse event questionnaires at 3 months. For these patients, the main baseline problems or complaints were musculoskeletal $(\mathrm{n}=2404,38 \%)$ and psychological $(\mathrm{n}=680,11 \%)$. Only $276(4.3 \%)$ reported that they were having their treatment paid for by the NHS and a large majority $(\mathrm{n}=6034,95.1 \%)$ were paying for treatment themselves. Regarding their pathway to acupuncture, $2535(39.9 \%)$ reported that "no one" had recommended acupuncture, $2082(32.8 \%)$ came via a family member, friend or colleague, and $614(9.7 \%)$ came through an NHS referral or recommendation. At the outset, $707(11.2 \%)$ had not had acupuncture before and 897 (14.1\%) reported no contact with their GP or hospital specialist either before or during the 3 month monitoring period. 376 patients $(5.9 \%)$ were treated by practitioners who had been in practice for less than 2 years. Patients in the

Table 2 Representativeness of patients: comparison between the 9408 patients who signed consent forms and the 6348 who also returned 3 month questionnaires

\begin{tabular}{|c|c|c|c|c|c|}
\hline & $\begin{array}{l}\text { Patients who signed } \\
\text { consent forms but did not } \\
\text { complete } 3 \text { month } \\
\text { questionnaires } \\
\text { (n=3060) }\end{array}$ & $\begin{array}{l}\text { Patients who completed } \\
3 \text { month questionnaires } \\
\text { ( } n=6348 \text { ) }\end{array}$ & Difference & $95 \% \mathrm{Cl}$ & p value \\
\hline Female & $2136(69.9 \%)$ & $4821(75.9 \%)$ & $-6.0 \%$ & $(-8.0 \%$ to $-4.1 \%)$ & 0.001 \\
\hline Aged under 40 & $946(30.9 \%)$ & 1423 (22.4\%) & $8.5 \%$ & $(6.6 \%$ to $10.4 \%)$ & 0.001 \\
\hline Mean (SD) age (years) & $49.2(15.4)$ & $51.9(14.5)$ & -2.7 & $(-3.3$ to -2.1$)$ & $0.001^{*}$ \\
\hline First time having acupuncture & $546(17.9 \%)$ & 707 (11.2\%) & $6.7 \%$ & $(5.2 \%$ to $8.3 \%)$ & 0.001 \\
\hline Paid for by NHS & $165(5.5 \%)$ & $276(4.3 \%)$ & $1.1 \%$ & $(0 \%$ to $2.1 \%)$ & 0.025 \\
\hline Prior GP or hospital contact & $2356(77.6 \%)$ & $4901(77.2 \%)$ & $-0.2 \%$ & $(-2.2 \%$ to $1.6 \%)$ & 0.87 \\
\hline $\begin{array}{l}\text { Patients whose practitioners had } \\
\text { less than } 2 \text { years experience }\end{array}$ & $240(7.8 \%)$ & $376(5.9 \%)$ & $1.9 \%$ & $(0.8 \%$ to $3.1 \%)$ & 0.001 \\
\hline
\end{tabular}


Box 1 Patient accounts of adverse events associated with admission to hospital or considered life threatening

Three patients reported that their adverse event was associated with admission to hospital or was life threatening:

- A patient with breast cancer and metastasis to her low back reported that the night after an acupuncture treatment she had "terrible back pain". The pain continued into the next day. In the afternoon she visited her GP who advised she admit herself to hospital for observation, worrying that her cancer had led to further deterioration of the spine. She spent one night in hospital, a "night of hell" because she was not allowed any painkillers. The next day she woke up and her back pain had completely disappeared. On reflection she was unsure whether her back pain had been caused by the acupuncture. Six months later she reported that she had had no back pain since and that she was continuing to receive regular acupuncture.

- A patient with ME reported having a very strong reaction to a treatment. A chicken pox like rash came up all over her body within a few hours and with it she felt feverish and "very ill". The spots turned to blisters, including in her mouth, her vagina and her eyelids. The rash gradually subsided over 4-5 days. However, she continued to feel ill "for several weeks". She did not contact her GP nor admit herself to hospital, saying that to have done so "would have been fatal". As the physical symptoms cleared she felt "a deep emotional pain" which she described as a "catharsis", out of which came a dramatic recovery from her ME symptoms. She then regained her energy and busy lifestyle such that, 3 months later, she described the treatment as a "miracle" and a "remarkable outcome". She had one more acupuncture treatment which she described as a "closure".

- A patient with alopecia crashed her car 2 days after an acupuncture treatment, fortunately not injuring herself. She had stayed up very late the night before the crash, the reason being that her boyfriend had not known about her alopecia, and so she was very concerned about his reaction. They stayed up talking till very late so she didn't get much sleep that night. The next day she "fell asleep at the wheel" which resulted in her car crash. On asking whether she thought that the acupuncture had caused her car crash, she said probably not, and that her extreme drowsiness was more likely to be due to the late night rather than the acupuncture received 2 days previously.

achieved sample reported an average of 4.8 acupuncture visits over the 3 months, a total of 30196 consultations for the sample as a whole.

\section{Direct adverse events}

682 patients $(10.7 \%)$ reported a total of 1044 adverse events caused directly by the acupuncture treatment. The most common event reported was "severe tiredness and exhaustion", followed by prolonged or unacceptable pain at the site of needling (table 3 ). Patients also spontaneously mentioned a number of adverse events under the category "other", most commonly bruising at the needling site. Three events were deemed to be "serious" by three patients $(0.5$ per 1000 patients over 3 months, 95\% CI 0.2 to 1.4 ), of which one was followed by admission to hospital and two were perceived as potentially life threatening; a summary of the details obtained from telephone interviews is given in box 1 . In terms of practitioner behaviour or equipment that might have been problematic, 109 (10\%) adverse events were deemed (post hoc) to be potentially avoidable-most commonly: needles being left in at the end of treatment $(n=55)$; moxibustion burns to the skin $(\mathrm{n}=28)$; perceived problems with electro-acupuncture such as too strong a current $(n=15)$; and being left alone too long $(n=10)$. The adverse event rate reported by the patients in relation to the 30196 consultations covered by this survey was 350 per 10000 consultations (95\% CI 330 to 370 ). Only 40 patients said they would not be willing to have acupuncture again.

In table 4 we present absolute and relative risks associated with acupuncture treatment. We also present the OR estimates of relative risk after adjustment for age, sex, and other covariates (number of treatments, whether patient had had acupuncture before, whether treatment was paid for by the NHS, whether patient had had contact with their GP or hospital specialist before or during the 3 month period, and practitioner's duration of practice) from a logistic regression analysis. Patients not funded by the NHS were less likely to report adverse events (adjusted OR 0.59), as were those patients who had not had contact with their GP or hospital specialist before or during the 3 month period (OR 0.66). However, patients were more likely to report adverse events if they had not had acupuncture before (OR 1.48) or if they were consulting a practitioner with less than 2 years experience (OR 1.44).

\section{Reports on advice about medication}

199 of the 6348 patients (3\%) reported that at some point over the 3 month period they were given advice from their acupuncturist to reduce or stop taking medication. On sending out an additional questionnaire to this group (but only to the 177 who had agreed to be contacted again), 99 responded. With additional information from four patients who were followed up by telephone, we were able to analyse further the data on advice about medication for 103 patients. For 36 patients in this subgroup (35\%) the advice was to stop rather than reduce their medication. In addition, 60 patients $(58 \%)$ also discussed this advice with their GP or hospital specialist. Six patients (1/1000 (95\% CI 0 to 2$)$ over 3 months) experienced adverse consequences as a result of advice about medication; none was serious. The adverse event data for the 103 patients are shown in table 5 .

\section{Reports of delayed diagnosis and treatment}

Over the 3 month period 660 patients (11\%) reported receiving advice from their acupuncturist to consult a GP or hospital specialist. Two patients $(0.3 / 1000$ over 3 months, 95\% CI 0 to 1) reported delayed conventional treatment as a result of consulting an acupuncturist. For one patient the adverse consequence was the cost of ineffective acupuncture for her jaw pain and for the other a prolonged urinary tract infection (see box 2).

\section{DISCUSSION}

In this study we have established from patients the type and frequency of adverse events that they associated with their acupuncture treatment. Of the 6348 patients participating, 682 reported at least one adverse event over 3 months, a rate of 107 per 1000 patients (95\% CI 100 to 115 ). The most common events reported were severe tiredness and exhaustion, pain at the site of needling, and headache. Only three of the reported adverse events could be classified as serious. Our secondary objective to establish whether patients are at risk 
Table 3 Type and frequency of patient reported "significant" adverse events experienced "as a result of acupuncture treatment"

\begin{tabular}{|c|c|c|c|c|}
\hline & \multirow{2}{*}{$\begin{array}{l}\text { Frequency of } \\
\text { reported } \\
\text { adverse events }\end{array}$} & \multirow{2}{*}{$\begin{array}{l}\text { Reported adverse } \\
\text { event rate/ } 1000 \\
\text { patients over } \\
3 \text { months }\end{array}$} & \multicolumn{2}{|c|}{$95 \% \mathrm{Cl}$} \\
\hline & & & Lower & Upper \\
\hline \multicolumn{5}{|c|}{ Event categories listed on questionnaire: treatment responses } \\
\hline Severe tiredness or exhaustion & 227 & 36 & 31 & 41 \\
\hline $\begin{array}{l}\text { Prolonged or unacceptable pain at site of } \\
\text { needling }\end{array}$ & 103 & 16 & 13 & 20 \\
\hline Severe headache or migraine & 77 & 12 & 10 & 15 \\
\hline $\begin{array}{l}\text { Unexpected, severe or prolonged worsening } \\
\text { of symptoms }\end{array}$ & 76 & 12 & 10 & 15 \\
\hline $\begin{array}{l}\text { Severe drowsiness (e.g. causing a potential } \\
\text { hazard on the road) }\end{array}$ & 53 & 8 & 6 & 11 \\
\hline Severe dizziness or vertigo or loss of balance & 48 & 8 & 6 & 10 \\
\hline Severe sleeplessness & 47 & 7 & 6 & 10 \\
\hline Severe stiffness or numbness & 41 & 7 & 5 & 9 \\
\hline $\begin{array}{l}\text { Skin infection affecting either local area where } \\
\text { needled or extensive area over body }\end{array}$ & 23 & 4 & 2 & 5 \\
\hline Diarrhoea & 23 & 4 & 2 & 5 \\
\hline Severe agitation & 22 & 4 & 2 & 5 \\
\hline Severe nausea & 22 & 4 & 2 & 5 \\
\hline Severe nightmares & 22 & 4 & 2 & 5 \\
\hline Severe panic & 16 & 3 & 2 & 4 \\
\hline Vomiting & 16 & 3 & 2 & 4 \\
\hline Fainting & 12 & 2 & 1 & 3 \\
\hline Uncontrolled euphoria & 11 & 2 & 1 & 3 \\
\hline Severe disorientation & 7 & 1 & 1 & 2 \\
\hline Fit or seizure & 0 & - & - & - \\
\hline \multicolumn{5}{|c|}{ Event categories listed on questionnaire: practitioner behaviour or equipment: } \\
\hline Needle left in & 55 & 9 & 7 & 11 \\
\hline Moxibustion burns to skin & 28 & 4 & 3 & 6 \\
\hline $\begin{array}{l}\text { Electro-acupuncture problems (e.g. too strong } \\
\text { a current resulting in pain) }\end{array}$ & 15 & 2 & 1 & 4 \\
\hline $\begin{array}{l}\text { Being left alone/unattended in the treatment } \\
\text { room for too long }\end{array}$ & 10 & 2 & 1 & 3 \\
\hline Needle breaking & 1 & $<1$ & 0 & 1 \\
\hline $\begin{array}{l}\text { Punctured internal organ such as needle } \\
\text { penetrating lung }\end{array}$ & 0 & - & - & - \\
\hline \multicolumn{5}{|c|}{ Other events mentioned spontaneously by respondents: } \\
\hline Bruising at needling site & 33 & 5 & 4 & 7 \\
\hline Other event & 27 & 4 & 3 & 6 \\
\hline Aches and pains (not specified) & 11 & 2 & 1 & 3 \\
\hline Emotional/psychological reaction & 8 & $\overline{1}$ & 1 & 2 \\
\hline Tiredness/drowsiness & 6 & 1 & 1 & 2 \\
\hline Bleeding at needling site & 4 & 1 & 0 & 2 \\
\hline Total & 1044 & & & \\
\hline
\end{tabular}

because they are consulting acupuncturists was not supported by the evidence from this study. We received reports of adverse but non-serious consequences related to advice about conventional (prescribed) medication from only six patients and delayed conventional treatment from only two.

This survey has considerably strengthened the evidence for the safety of acupuncture in routine practice. Patients had little difficulty in responding to questions about their experiences of adverse events associated with the acupuncture they received during the preceding 3 months. The implications are relevant to policy developments in the field and the current moves in the UK towards statutory regulation of acupuncturists.

The patient data from this survey are different from those which would have been provided by their practitioners and, arguably, are more robust on the basis of evidence from a systematic review of prospective acupuncture safety studies. ${ }^{14}$ For example, the adverse event rate reported by the patients in this study ( 350 per 10000 treatments (95\% CI 330 to 370)) is considerably higher than the rate reported by acupuncturists in an earlier survey of practitioners from the same professional body ( 13 per 10000 (95\% CI 9 to 17$)) .{ }^{5}$ While some of this disparity might be explained by different definitions of adverse events, other factors likely to play a part include under-reporting by practitioners, perhaps due to sensitivity to criticism, and over-reporting by patients due to the use of checklists with tick boxes. The events listed in our survey tool were usually given the descriptor "severe". It is possible that patients would have distinguished between severe events and others given the choice, and may have over-reported severe events. This is supported by the finding that very few (only 40) patients regarded their experience of adverse events to be such that it would deter them from trying acupuncture again in the future.

There were $109(10 \%)$ adverse events that might be considered potentially avoidable on the basis that they could only happen if acupuncture procedures were executed poorly. For most types of avoidable events, patients reported higher proportions than did acupuncturists in practitioner surveys. ${ }^{5614}$ It is unlikely that the "skin infections" were caused by poor practice as the mandatory requirement that practitioners use sterile disposable needles should preclude cross infection. Such skin reactions are more likely to be due either to a local allergic response to chrome or 
Table 4 Adverse event rates and relative risks associated with acupuncture treatment

\begin{tabular}{|c|c|c|c|c|}
\hline & $\begin{array}{l}\text { No of patients reporting } \\
\text { an adverse event over } 3 \\
\text { months/total reporting }\end{array}$ & $\begin{array}{l}\text { Crude rate of patients reporting } \\
\text { adverse events } / 1000 \text { patients } \\
\text { over } 3 \text { months }(95 \% \mathrm{CI})\end{array}$ & $\begin{array}{l}\text { Unadjusted relative risk } \\
\text { OR }(95 \% \mathrm{CI})\end{array}$ & $\begin{array}{l}\text { Adjusted relative risk } \\
\text { OR }(95 \% \mathrm{Cl})\end{array}$ \\
\hline \multicolumn{5}{|c|}{ Absolute risk of reporting at least one direct adverse event } \\
\hline All patients & $682 / 6348$ & 107 (100 to 115$)$ & & \\
\hline \multicolumn{5}{|c|}{ Relative risk of reporting at least one direct adverse event } \\
\hline$M v F$ & $121 / 1527$ v $561 / 4821$ & & $\begin{array}{l}0.65(0.53 \text { to } 0.80) \\
p<0.001\end{array}$ & $\begin{array}{l}0.62(0.50 \text { to } 0.77) \\
p<0.001\end{array}$ \\
\hline Age $\geqslant=40 v<40$ & $477 / 4869$ v 194/1423 & & $\begin{array}{l}0.69(0.58 \text { to } 0.82) \\
p<0.001\end{array}$ & $\begin{array}{l}0.74(0.61 \text { to } 0.89) \\
p=0.001\end{array}$ \\
\hline $\begin{array}{l}\geqslant 6 \vee 1-5 \text { treatments over } \\
3 \text { months }\end{array}$ & $315 / 1980$ $348 / 4229$ & & $\begin{array}{l}2.11(1.79 \text { to } 2.48) \\
p<0.001\end{array}$ & $\begin{array}{l}1.92(1.62 \text { to } 2.28) \\
p<0.001\end{array}$ \\
\hline $\begin{array}{l}\text { First time having acupuncture } \\
v \text { had acupuncture before }\end{array}$ & $116 / 707$ v 565/5622 & & $\begin{array}{l}1.76(1.40 \text { to } 2.18) \\
p<0.001\end{array}$ & $\begin{array}{l}1.48(1.18 \text { to } 1.87) \\
p=0.001\end{array}$ \\
\hline $\begin{array}{l}\text { Not paid for by NHS } \\
v \text { paid for by NHS }\end{array}$ & $622 / 6034$ v 53/276 & & $\begin{array}{l}0.48(0.35 \text { to } 0.66) \\
p<0.001\end{array}$ & $\begin{array}{l}0.59(0.43 \text { to } 0.82) \\
p=0.002\end{array}$ \\
\hline $\begin{array}{l}\text { No contact with GP or specialist } \\
\text { v contact with GP or specialist }\end{array}$ & $58 / 897$ v $623 / 5428$ & & $\begin{array}{l}0.53(0.40 \text { to } 0.71) \\
p<0.001\end{array}$ & $\begin{array}{l}0.66(0.50 \text { to } 0.88) \\
p=0.005\end{array}$ \\
\hline In practice $<2$ years $v \geqslant 2$ years & $60 / 376$ v $622 / 5972$ & & $\begin{array}{l}1.63(1.22 \text { to } 2.17) \\
p<0.001\end{array}$ & $\begin{array}{l}1.44(1.06 \text { to } 1.95) \\
p=0.019\end{array}$ \\
\hline \multicolumn{3}{|c|}{ Absolute risk of patients reporting an indirect adverse event } & & \\
\hline $\begin{array}{l}\text { Symptoms worsening after } \\
\text { following advice from } \\
\text { acupuncturists about medication }\end{array}$ & $6 / 6348$ & $0.9(0.4$ to 2.1$)$ & & \\
\hline Delayed conventional treatment & $2 / 6348$ & $0.3(0$ to 1.1$)$ & & \\
\hline
\end{tabular}

Table 5 Patient reports of the medication for which advice was given by acupuncturists and adverse consequences $(n=103$ )

\begin{tabular}{|c|c|c|c|c|c|}
\hline & $\begin{array}{l}\text { Number advised to } \\
\text { reduce or stop } \\
\text { medication }\end{array}$ & $\begin{array}{l}\text { Number advised } \\
\text { to stop medication }\end{array}$ & $\begin{array}{l}\text { Number who also } \\
\text { discussed advice with } \\
\text { their GP or hospital } \\
\text { specialist }\end{array}$ & $\begin{array}{l}\text { Number with an } \\
\text { adverse event }\end{array}$ & $\begin{array}{l}\text { Key symptoms of } \\
\text { adverse events }\end{array}$ \\
\hline Antidepressants & 24 & $8(33 \%)$ & $16(67 \%)$ & 3 & $\begin{array}{l}\text { Increased anxiety } \\
\text { Increased depression } \\
\text { "Withdrawal symptoms" }\end{array}$ \\
\hline Steroids: prednisolone & 5 & 0 & 3 & & \\
\hline Steroid inhaler & 6 & 0 & 4 & & \\
\hline Hydrocortisone & 1 & 1 & 1 & 1 & Skin cracking \\
\hline Total corticosteroids & 12 & $1(8 \%)$ & $8(67 \%)$ & & \\
\hline NSAIDs & 11 & $2(18 \%)$ & $6(55 \%)$ & & \\
\hline Oral contraceptives & 2 & 2 & 2 & & \\
\hline HRT & 4 & 3 & 2 & 1 & Hot flushes \\
\hline Hormone treatment for acne & 1 & 1 & 0 & & \\
\hline Thyroxine & 3 & 1 & 3 & & \\
\hline Total hormonal drugs & 10 & $7(70 \%)$ & $7(70 \%)$ & & \\
\hline Analgesics & 7 & $1(14 \%)$ & $3(43 \%)$ & & \\
\hline Antihistamines & 5 & $3(60 \%)$ & $2(40 \%)$ & & \\
\hline Beta blockers & 4 & $1(25 \%)$ & $3(75 \%)$ & & \\
\hline Antimigraine & 4 & $2(50 \%)$ & $1(25 \%)$ & & \\
\hline Proton pump inhibitors & 2 & 1 & 1 & & \\
\hline Antibiotics & 2 & 1 & 2 & & \\
\hline ACE inhibitors & 2 & 1 & 2 & & \\
\hline Antispasmodic & 2 & 1 & 1 & & \\
\hline Laxative & 2 & 1 & 1 & & \\
\hline Bronchodilator & 2 & 0 & 0 & & \\
\hline Miscellaneous & 13 & 5 & 6 & & \\
\hline Total "other" & 25 & $10(40 \%)$ & $13(52 \%)$ & & \\
\hline Unknown medication & 1 & & & 1 & $\begin{array}{l}\text { Worsening of chronic fatigue } \\
\text { syndrome }\end{array}$ \\
\hline Total & 103 & $36(35 \%)$ & $60(58 \%)$ & & \\
\hline
\end{tabular}


Box 2 Patient accounts of delayed conventional treatment as a result of receiving acupuncture

Two patients reported that their acupuncture resulted in delayed conventional treatment:

- A patient received acupuncture for what she described as a "left face jaw problem". After several sessions the pain in her jaw suddenly got "very bad" after a treatment. She ceased acupuncture immediately and went to her dentist who extracted a tooth. She no longer has had any pain in that area. The acupuncture, which had only given her "intermittent relief", not only delayed a successful outcome but also cost her $£ 210$ compared with $£ 20$ at the dentist.

- A patient was confined to a wheelchair having being affected by spinal injuries from the neck down. She consulted an acupuncturist for help with a urinary tract infection. Despite the acupuncture, her urinary symptoms continued to deteriorate. Initially she "had not thought" to consult her GP, but did so when her symptoms deteriorated further. Her GP prescribed three courses of antibiotics. The delay in consulting her GP led to a "prolonged infection". Following this experience, the patient chose to continue to receive acupuncture and she reported a subsequent urinary tract infection that was successfully treated with acupuncture.

nickel in the needles or a systemic response to the treatment itself.

This survey provides some valuable lessons for practitioners and educationalists. Firstly, patients appear to be most at risk of tiredness and exhaustion after treatment, leading to concerns about car accidents on driving away afterwards. Practitioners need to alert patients to this risk before treatment and to monitor levels of wooziness or light headedness on leaving the treatment room and before driving home. Ironically, for the one patient in this survey who reported a car accident, the association with acupuncture is extremely unlikely as it occurred 2 days after treatment. Given that $5 \%$ of adverse events involved needles being left in by mistake, practitioners need to take extra care in counting needles in and out. With 3\% of adverse events involving moxibustion burns, the need for practitioners to take extra care in this area is also indicated by, for example, adhering to current practice guidelines requiring acupuncturists always to remain in the treatment room while using moxibustion.

Concerns in the literature have been raised about the safety of patients treated by non-physician practitioners who provide acupuncture outside national health care institutions. ${ }^{3411}$ The findings of this study suggest that these issues are not a major cause for concern for patients consulting this group of professionally registered acupuncturists. Patients potentially at greater risk-namely, those consulting outside the NHS and those who had no contact with their GP or hospital specialist before or during the course of treatmentreported significantly lower rates of adverse events.

From the data on advice about prescribed medication and delayed diagnosis and treatment, the evidence does not lead to concerns about patient safety. Advice from GPs or specialists about taking conventional medication was to reduce rather than to stop in more than half the cases; the drugs most commonly involved were antidepressants, corticosteroids, non-steroidal anti-inflammatory drugs, and hormonal drugs. The adverse consequences experienced by the

\section{Key messages}

- Patients' experiences of adverse events make a useful contribution to our understanding of acupuncture safety.

- Evidence from patients has reinforced previous evidence from practitioners that acupuncture is safe in competent hands.

- Concerns about high rates of adverse events caused by acupuncturists giving advice about conventional medication or causing delayed diagnosis and treatment are not substantiated.

- There is no evidence that patients who consult acupuncturists outside the NHS are at greater risk, even if the patients have had no contact with a general practitioner or hospital specialist.

six patients were not serious. Particular concern would be raised if patients were stopping their asthma medication, but our evidence shows that none of the 11 patients who reported taking prednisolone or steroid inhalers were advised to discontinue. Reports of delayed treatment were also infrequent and involved only two patients, both of whom experienced non-serious consequences.

While the evidence from patients might be subject to less response bias than that of practitioners, a number of potential limitations to this study remain. The subjectivity of patients' reports must be considered, given the possibility of over- or under-reporting and the potential for misattribution. The 3 month period for monitoring may have been too short for adverse events that are rare or take time to manifest. However, a period of more than 3 months may have increased recall bias, with some patients remembering adverse events less well if they happened early on in the monitoring period.

There is the possibility that non-serious adverse events are clustered within acupuncturists and within treatments rather than distributed randomly. Such clustering would increase the width of the confidence intervals but would not alter the point estimates. In a trade-off to maximise practitioner and patient participation, our design precluded the possibility of linking reported events to individual practitioners or treatments. This meant that we were not able to test for clustering effects.

We found evidence of a difference in the patient characteristics of responders and non-responders to the survey at 3 months. We also found some evidence that the characteristics of the acupuncturists who agreed to take part in the survey and allow access to their patients may differ from those who refused to be involved in the survey. These factors may limit the generalisability of our findings. However, the large sample size and reasonable response rate $(67 \%)$ to the survey should mitigate against this possibility.

Future research could usefully explore in more depth why almost all patients (94\%) who experienced an adverse event continued to be willing to have acupuncture. For some patients the adverse event was an aggravation of existing symptoms, something that has been called a "healing crisis" when followed by an overall improvement of symptoms. ${ }^{9}{ }^{15}$ In addition, qualitative research could usefully explore how patients weigh up the perceived cost of an adverse event with the perceived benefit of acupuncture. Given that patients may also be interested in choosing between acupuncture and conventional treatment, future research could also compare 
risk profiles between interventions for common conditions such as chronic pain.

\section{CONCLUSION}

Patient reports of serious adverse events associated with acupuncture were rare. Adverse events related to advice about medication and delayed conventional treatment were also infrequent. There was no evidence that patients seeking treatment outside the NHS were at greater risk. While acupuncture treatment is associated with a range of adverse effects, these are not sufficient to prevent most patients seeking further acupuncture. This prospective study provides strong evidence that acupuncture, when practised by regulated practitioners, is a safe intervention.

\section{Authors' affiliations}

H MacPherson, T Scullion, Foundation for Traditional Chinese Medicine, York, UK

K J Thomas, Medical Care Research Unit, University of Sheffield, Sheffield, UK

S Walters, Sheffield Health Economics Group, School of Health and Related Research, University of Sheffield, Sheffield, UK

HM initiated the project, coordinated all aspects of the study, and is the guarantor. KJT and SW contributed to study design, data analysis, interpretation of results, and manuscript drafting. TS managed the dayto-day work of mailings, data inputting, and much data analysis. Julie Elrick assisted in the early stages of the project and in piloting the documentation. Trevor Sheldon helped in the final drafting the manuscript. External scientific advisors included Alan Bensoussan, Stephen Birch, Alan Breen, Roy Carr-Hill, Mike Fitter, Charles Vincent and Adrian White. The study was supported by a grant from the British Acupuncture Council.

\section{REFERENCES}

1 British Medical Association Board of Science and Education. Acupuncture: efficacy, safety and practice. London: Harwood Academic Publishers, 2000.

2 House of Lords. Complementary and alternative medicine, Report of the Select Committee on Science and Technology. London: Stationery Office, 2000.

3 Ernst E. Desktop guide to complementary and alternative medicine: an evidence based approach. London: Mosby Harcourt, 2001.

4 Bensoussan A, Myers SP. Towards a safer choice: the practice of traditional Chinese medicine in Australia. Faculty of Health, University of Western Sydney: McArthur, 1996.

5 MacPherson H, Thomas KJ, Walters S, et al. The York acupuncture safety study: prospective survey of 34,000 treatments by traditional acupuncturists. BMJ 2001;323:486-7.

6 White A, Hayoe S, Hart A, et al. Adverse events following acupuncture: prospective survey of 32000 consultations with doctors and physiotherapists. BMJ 2001;323:485-6

7 Vincent C. The safety of acupuncture. BMJ 2001;323:467-8.

8 Vincent C, Coulter A. Patient safety: what about the patient? Qual Saf Health Care 2002;11:76-80.

9 MacPherson $\mathrm{H}$, Thomas KJ, Walters $\mathrm{S}$, et al. A prospective survey of adverse events and treatment reactions following 34,000 consultations with professional acupuncturists. Acupunct Med 2001;19:93-102.

10 Thomas KJ, Nicholl J, Coleman P. Use and expenditure on complementary medicine in England: a population-based survey. Complement Ther Med 2001;9:1-11.

11 Norheim AJ, Fonnebo V. Adverse effects are more than just case reports: results from questionnaires among 1135 randomly selected doctors and 197 acupuncturists. Complement Ther Med 1996;4:8-13.

12 Lazarou J, Pomeranz BH, Corey PN. Incidence of adverse drug reactions in hospitalized patients. A meta-analysis of prospective studies. JAMA 1998;279:1200-5

13 Edwards IR, Aronson JK. Adverse drug reactions: definitions, diagnosis, and management. Lancet 2000;356:1255-9.

14 Ernst, E, White AR. Prospective studies of the safety of acupuncture: a systematic review. Am J Med 2001;110:481-5.

15 Yamashita H, Tsukayama H, Noti N, et al. Incidence of adverse reactions associated with acupuncture. J Altern Complement Med 2000;6:345-50.

\section{$\mathrm{ECHO}$}

\section{Changing clinical behaviour by making guidelines specific}

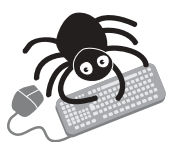

Please visit the Quality and Safety in Health Care website [www. qshc.com] for a link to the full text of this article.
$T$ he uptake of guidelines could be improved simply by changing their wording, suggest clinical psychologists. The more precisely behaviours are specified, they argue, the more likely they are to be carried out. Their advice is to use language that is behaviourally precise and to use active verbs, avoiding general exhortations (should) and general descriptions (may).

As an example, the researchers looked at guidelines from the National Institute for Clinical Excellence for the management of schizophrenia. The recommendations from these guidelines, like many, are at risk of being buried and not implemented. The researchers reworded the recommendations using behavioural terms such as what and who, adding that when, where and how could equally be used. Rewording the recommendations in this way they were able to identify areas of uncertainty in their implementation.

The researchers also showed that specifying behaviour precisely allows the barriers or facilitators to change to be looked at, so that future guidelines can be adapted accordingly. Known as ABC (antecedents, behaviour and consequences) it allows for the systematic investigation into the way that behaviour is linked to what occurs before the implementation of a guideline (the antecedents) and what occurs afterwards (the consequences).

Future research is now needed to support these views, and suggestions include a comparison of the implementation of guidelines before and after they have been rewritten in behaviourally specific terms.

\ BMJ 2004;328;343-345 